\title{
Anti-endometriotic Effects of Ceratonia Siliqua L. Pod on Endometrial Mesenchymal Stromal/stem Cells Isolated from Women with Endometriosis- associated Infertility
}

\section{Zahra Khodabandeh}

Shiraz University of Medical Sciences

\section{Bahia Namavar Jahromi}

Shiraz University of Medical Sciences

Atefe Hashemi

Shiraz University of Medical Sciences

\section{Alireza Afshar}

Bushehr University of Medical Sciences

\section{Neda Baghban}

Bushehr University of Medical Sciences

Kamran Hessami

Shiraz University of Medical Sciences

Gholamhossein Mohebbi

Bushehr University of Medical Sciences

Alireza Barmak

Bushehr University of Medical Sciences

Iman Jamhiri

Shiraz University of Medical Sciences

\section{Shahrokh Zare}

Shiraz University of Medical Sciences

\section{Parmis Badr}

Shiraz University of Medical Sciences

Ida Iraji

Shiraz University of Medical Sciences

\section{Tahere Poordast}

Shiraz University of Medical Sciences

Arezoo Khoradmehr

Bushehr University of Medical Sciences

Amin Tamadon ( $\sim$ amintamaddon@yahoo.com )

Bushehr University of Medical Sciences https://orcid.org/0000-0002-0222-3035 


\section{Research Article}

Keywords: endometriosis, Ceratonia siliqua, gene expression, endometrial stem cells

Posted Date: December 20th, 2021

DOl: https://doi.org/10.21203/rs.3.rs-840194/v1

License: (c) (1) This work is licensed under a Creative Commons Attribution 4.0 International License. Read Full License 


\section{Abstract}

This study investigated the effects of carob (Ceratonia siliqua L.) pod extract (CPE) on human endometrial stem cells (ESCs) viability and to examine its impact on mRNA expression of methyltransferase (DNMT-1, DNMT-3A and DNMT-3B), histone deacetylase-1 (HDAC-1), matrix metalloproteinase-2 (MMP-2) and cyclooxygenase-2 (COX-2) in endometriotic patients. The ESCs were derived from endometrium of patients with endometrioma (OMA-ESCs) and deep infiltrative endometriosis samples of 10 women with endometriosis associated infertility (E-ESCs) were compared to the ESCs derived from endometrium of endometriosis free, normal women as control group (C-ESCs). The metabolic activity of control and case groups was evaluated by treating them with different concentrations of CPE. In the E-ESCs, treatment with 0.8 and $2 \mu \mathrm{g} / \mathrm{mL}$ of CPE resulted in downregulation of COX-2 and HDAC- 1 compared to the control group ( $p=0.02$ and $p=0.02$, respectively). Treatment with $0.8 \mu \mathrm{g} / \mathrm{mL}$ of CPE decreased MMP-2 and DNMT-3B genes expression ( $p=0.02$ and $p=0.03$, respectively). Furthermore, COX-2 and DNMT-3A genes were significantly upregulated after treatment with $2 \mu \mathrm{g} / \mathrm{mL}$ of CPE. Expression of the COX-2, HDAC-1, DNMT-1, DNMT-3A, and DNMT-3B peptides decreased in E-ESCs, OMA-ESCs and C-ESCs after treatment with 0.8 and $2 \mu \mathrm{g} / \mathrm{mL}$ concentrations of the CPE. The GC analysis of the CPE resulted in 14 compounds with interactions with the target proteins through the docking process. In vitro CPE treatment significantly downregulated cell inflammatory pathway involved in the pathophysiology of endometriosis and may be a potential agent for treatment of endometriosis.

\section{Introduction}

Endometriosis is a chronic disorder generally identified by abnormal growth and adherence of functional endometrial tissue outside the uterine cavity and is a common cause of chronic pelvic pain and infertility in reproductive aged women. It has been estimated that $20-50 \%$ of infertile women suffer from endometriosis and that $30-50 \%$ of women with endometriosis are sub-fertile or infertile (Parasar et al. 2017). Various theories have been proposed to explain the pathophysiology of endometriosis, but no single theory has been able to provide adequate insight into the exact pathogenesis and process of the disease (Colon-Diaz et al. 2012).

Over the recent years, there has been growing evidence suggesting that genetic and epigenetic factors play important roles in the development of endometriosis (Guo 2009). DNA methyltransferases (DNMTs) namely DNMT1, DNMT3A, and DNMT3B - which maintain CpG methylation, along with histone deacetylases (HDACs) play central roles in epigenetic regulation of cancers (Colon-Diaz et al. 2012; Yang et al. 2011). Since endometriosis exhibits malignant-like features, previous studies found that the aberrant expression of DNMT1, DNMT3A, DNMT3B, and HDAC1 genes were more prominent in women with endometriosis (Koukoura et al. 2016; Wu et al. 2007; Xiaomeng et al. 2013).

Over-expression of cyclooxygenase-2 (COX-2), and the subsequent increased prostaglandin E2 (PGE2) level are the main causes of dysmenorrhea and recurrence of the endometriotic lesions (Buchweitz et al. 2006; Koukoura et al. 2016). Matrix metalloproteinase-2 (MMP-2) is another well-known factor that has 
been shown to be involved in endometriosis development (Huang et al. 2004). MMP-2 contributes to the degradation of collagens and other components of extracellular matrix and basement membrane,

resulting in disseminated malignancies (lurlaro et al. 1999) and a similar mechanism is probably involved in pathogenesis of endometriosis (Chung et al. 2002; Huang et al. 2004).

Various medical and surgical strategies have been used for the management of endometriosis; however, current approaches are not completely effective and on top of that, bear major side effects (Vignali et al. 2005; Zhao et al. 2015). Therefore, novel medical agents from traditional medicine might prove effective through targeting the biological pathways involved in endometriosis and seem necessary to be examined for improving the treatment outcome.

C. siliqua, commonly known as carob, is an evergreen tree belonging to the Leguminosae family, which is widely grown in Mediterranean countries. It has been used in folk medicine to treat diverse disorders such as diabetes mellitus, dyslipidemia, and various gastrointestinal ailments (Goulas et al. 2016). C. siliqua is generally called "kharnoub-e-shami" in Traditional Persian Medicine (TPM) manuscripts and anti-

menorrhagic and anti-infertility activities along with other gynecological benefits have been noted for this medicinal plant (Mobli et al. 2015; Tansaz et al. 2016). Furthermore, this natural product has been used since old times for improving fertility by indigenous people in Middle Eastern countries (Fata et al. 2019). C. siliqua's main constituents are gum, protein, and polyphenols, of which the latter one is mainly responsible for anti-inflammatory, antioxidant, and anti-ulcer activities (Goulas et al. 2016; Rtibi et al. 2017). Methanolic extract of $C$. siliqua as well as its main phenolic compounds, catechin and gallic acid, have been shown to significantly diminish viability of cervical and breast cancer cells in concentrationand time- dependent manners (Custódio et al. 2011; Custódio et al. 2013).

To the best of our knowledge, this is the first study to investigate the effect of CPE on gene and peptide expression of DNMT1, DNMT3A, DNMT3B, HDAC1, MMP2, and COX 2 in endometrial stem cells (ESCs) isolated from women with endometriosis-associated infertility.

\section{Materials And Methods}

\subsection{Ethics and consents}

The study was approved by the Institutional Review Board and related Ethics Committee of Shiraz University of Medical Sciences (Ethics code: IR.SUMS.REC.1397.555). After thorough explanation of the study design, informed consents were obtained from all of the participants and donors prior to sample collection.

\subsection{Patients and tissue samples}

Endometrial stem cells (ESCs) were obtained from endometrium and endometrioma, and deep infiltrative endometriosis (DIE) samples of ten women with endometriosis-associated infertility (E-ESCs) and then, were compared to the ESCs derived from endometrium of one endometriosis free normal woman as our 
control group (C-ESCs). DIE samples were obtained from the rectovaginal septum and deep retroperitoneal portions of women with endometriosis associated infertility (EAI) and ectopic endometrial cells were derived from ovarian endometriosis cysts (OMA-ESCs).

Among women with EAI who referred to the laparoscopy clinic of Obstetrics and Gynecology department at Shiraz University of Medical Sciences (SUMS), ten candidates of laparoscopic endometriosis surgery were included and those women who had received GnRH agonist, progesterone or other hormones 3 months before the study were excluded. All of the included cases had surgical and histological evidence of stage III or IV endometriosis, according to American Society of Reproductive Medicine classification (Canis et al. 1997). Endometrial samples were taken from endometrial cavity as ectopic endometrial cells by dilatation and curettage ( $D$ and $C$ ). Also, samples of eutopic endometrial cells were taken from ovarian endometriosis cysts (endometrioma) and DIE lesions by laparoscopic intervention. Eutopic and ectopic endometrial samples were taken by laparoscopic surgical team of SUMS. Also, eutopic endometrial cells were taken from a normal, endometriosis-free woman who was scheduled for a benign gynecologic surgery by $D$ and $C$ to serve as our cellular control group.

The cellular samples were classified into 3 groups; Group-1 consisted of eutopic endometrial cells derived from EAI women (E-ESCs), group-2 included the ectopic endometrial cells derived from ovarian endometriosis cysts and DIE from EAI women (OMA-ESCs) and group-3 which included eutopic endometrial cells that were taken from normal endometriosis free woman (C-ESCs).

\subsection{Preparation of $\mathrm{CPE}$}

The CPE were purchased from the herbal market in Shiraz, Iran. The plant material was authenticated in the Phytopharmaceutical Department of Shiraz University of Medical Sciences, Shiraz, Iran by a botanist and given a voucher specimen number (PM-1292), which was deposited in the herbarium. The extract was obtained through the following steps: $C$. siliqua pods were powdered and sieved through mesh with the size of $50 \mu \mathrm{m}$. Then, $100 \mathrm{~g}$ of the prepared CPE was added to $500 \mathrm{~mL}$ of Ethanol $70 \%$ and the suspension was shaken at room temperature for 24 hours. After filtration, the supernatant at 200000 $\mu \mathrm{g} / \mathrm{mL}$ concentration was stored at $-20^{\circ} \mathrm{C}$ for the next steps of the study.

\subsection{Phytochemical analysis: determination of total phenolic content (TPC)}

The total phenolic content (TPC) of the extract was evaluated by Folin-Ciocalteu method (Attard, 2013).

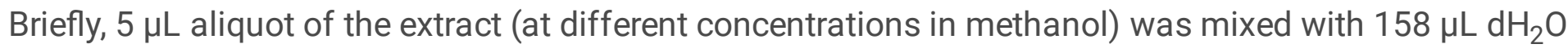
followed by the addition of $10 \mu \mathrm{L}$ Folin Ciocalteu's reagent. Then, $30 \mu \mathrm{L}$ of $15 \%$ sodium carbonate was added. The mixture was incubated at room temperature for $45 \mathrm{~min}$ in the dark and the absorbance was measured at $765 \mathrm{~nm}$ using microplate reader (POLAR star Omega, BMG lantech, Germany). The standard curve was measured based on the prepared gallic acid standard solution $(0,10,50,100,150,250$ and 500 $\mathrm{mg} / \mathrm{mL}$ ) which revealed the linear regression $\mathrm{r}^{2}>0.99$. The phenolic level was expressed as milligrams of 
gallic acid equivalents (GAE) per gram of dry plant extract (mg gallic acid/g dry extract). Assessment of each sample was done in triplicate (Ardakani Movaghati et al. 2019; Ostovar et al. 2020).

\subsection{GC-MS analysis of CPE}

After lyophilization of the CPE, it was subjected to the 7890B Agilent Gas Chromatography-Mass Spectroscopy (GC-MS). Electron ionization (EI) mass spectra with scan range of $\mathrm{m} / \mathrm{z}$ 50-500 was obtained using electrons with energy of $70 \mathrm{eV}$. Moreover, the filament emission was set out on $0.5 \mathrm{~mA}$. For GC separations, an HP-5MS UI column with $30 \mathrm{~m} \times 0.25 \mathrm{~mm}$ i.d. and film thickness of $0.5 \mu \mathrm{m}$ were used. Helium was used with the flow of $0.8 \mathrm{ml} / \mathrm{min}$ for El as a carrier gas. The temperature of GC oven was set at $5^{\circ} \mathrm{C} / \mathrm{min}$ from $80^{\circ} \mathrm{C}$ after 3 min since the sample injection and held at $250^{\circ} \mathrm{C}$ for $10 \mathrm{~min}$. The transfer line, ion source, and injection port of the gas chromatograph of 5977MSD were maintained at $250^{\circ} \mathrm{C}, 220^{\circ} \mathrm{C}$, and $240^{\circ} \mathrm{C}$, respectively. The separated compounds were identified using compounds comparison with the compound data of the National Institute of Standards and Technology (NIST MS database, 2014) library.

\subsection{Determination of antioxidant activity: DPPH + free radical scavenging assay}

The in vitro antioxidant activity was measured based on the decolorization of the DPPH [(1, 1-diphenyl-2picrylhydrazyl)] as described previously (Lachkar et al. 2016). Briefly, $20 \mu \mathrm{L}$ of crude extract at different concentrations or quercetin as a positive control was added to $180 \mu \mathrm{L}$ of $110 \mu \mathrm{M}$ DPPH radical dissolved in methanol. The reagent was incubated in darkness for $30 \mathrm{~min}$. Methanol was used as a blank solution. The pale-yellow color of the reduced DPPH radical was measured at an optical density of $517 \mathrm{~nm}$ at room temperature using microplate reader (POLAR star Omega, BMG lantech, Germany). The volume of antioxidant required to produce a $50 \%$ reduction of the $\mathrm{DPPH}$ was recorded as $\mathrm{IC}_{50}$ value. $\mathrm{A}$ lower $\mathrm{IC}_{50}$ value confirmed a stronger DPPH scavenging capacity (Koohi-Hosseinabadi et al. 2017).

\subsection{Human endometrial stem cells (ESCs) isolation, culture and treatment design}

The ESCs isolation procedure was based on methods described earlier with some modifications (Fernandez-Shaw et al. 1992). Briefly, tissues were minced into small pieces of about 1-2 $\mathrm{mm}^{3}$ and digested in the presence of $1 \mathrm{mg} / \mathrm{mL}$ of collagenase type 1(Cat.No.17100-017, Gibco) in Dulbecco's modified eagle medium (DMEM, Biovet, Bulgaria) containing 10\% fetal bovine serum (FBS, Biovet, Bulgaria), stirred for $1 \mathrm{~h}$. After that, the cell suspension was filtered through 40 micrometer nylon sieve for removal of undigested aggregates. Ficoll (REF 002041600, Gibco) was used to remove red blood cells. The cell suspension was seeded in T25 culture flasks and incubated in DMEM/F12 medium (SigmaAldrich, UK) containing 10\% FBS, $100 \mu \mathrm{g} / \mathrm{mL}$ Penicillin, and $100 \mathrm{U} / \mathrm{mL}$ Streptomycin (Sigma, USA) until cells reached $80 \%$ confluency. Then, they were used for subsequent experiments. Interestingly, the DIE cells did not have any growth and proliferation in the culture medium and no stem cells could be obtained 
from those samples. But the ESC isolation procedure was successfully performed on eutopic endometrial cells from the EAl, normal control women and also from ectopic ovarian endometriosis cysts (OMA).

\subsection{Surface marker characterization}

To assess the purity of the cells in three groups (E-ESCs, OMA-ESCs and C-ESCs), flow cytometry was used and cells were categorized by expression of cell surface markers at the third passage. The resulting suspension was washed in blocking solution, cold phosphate buffer saline (PBS) containing $10 \%$ FBS, for 20 minutes. Then, they were labeled with FITC (Fluorescein isothiocyanate)-conjugated anti-CD 45, antiCD90, anti-CD73, and anti-CD31 antibodies (all from Abcam, UK, Cambridge). Subsequently, the cells were washed twice and resuspended in cold PBS. The percentage of positive or negative cells was evaluated using a calibrated FACS device (FACS Calibur ${ }^{\mathrm{TM}}$, BD Biosciences) and analyzed by Flow Jo software (BD Bioscineces).

\subsection{Multilineage differentiation potential of ESCs}

To evaluate multipotency of the isolated cells, they were differentiated into two different mesenchymal lineages: osteocytes and adipocytes. $1 \times 10^{4} \mathrm{cells} / \mathrm{cm}^{2}$ at $3 \mathrm{rd}$ passage were cultured in 24 well plates. Once the cells reached about $80 \%$ confluence, the growth medium was changed to osteogenic medium (containing DMEM-LG supplemented with 10\% FBS, $2 \mathrm{mM} \mathrm{L-glutamine,} 100 \mathrm{U} / \mathrm{mL}$ penicillin, $100 \mu \mathrm{g} / \mathrm{ml}$ streptomycin, $100 \mathrm{nM}$ dexamethasone, $0.2 \mathrm{mM}$ L-ascorbate and $10 \mathrm{mM} \beta$-glycerophosphate) and adipogenic medium (containing DMEM-LG supplemented with 10\% FBS, 2 mM of L-glutamine, $100 \mathrm{U} /$ $\mathrm{mL}$ penicillin, $100 \mu \mathrm{g} / \mathrm{ml}$ streptomycyne, $60 \mu \mathrm{M}$ indomethacin, $1 \mu \mathrm{M}$ dexamethasone, $0.5 \mathrm{mM}$ of IBMX and $5 \mu \mathrm{g} / \mathrm{mL}$ Insulin solution). The osteogenic and adipogenic cells were incubated for 28 and 21 days, respectively. Half of the medium was replaced every 3 days. For assessment of differentiation, both differentiated cell lines were fixed in $4 \%$ paraformaldehyde, then stained with alizarin red and oil red to observe differentiated osteoblasts and adipocytes, respectively.

\subsection{Assessment of proliferation capacity and cell viability by 3-(4, 5-dimethylthiazol - 2-yl)-2, 5-dipheyl tetrazolium (MTT) assay}

Proliferation capacity and cell viability of E-ESCs, OMA-ESCs and C-ESCs were determined using the 3-(4, 5-dimethylthiazol-2-yl)-2, 5-dipheyl tetrazolium (MTT) assay (Sigma-Aldrich). Cells were seeded in 96 well plates at a density of 5000 cells/well. After $24 \mathrm{~h}$ incubation, different CPE concentrations (ranging from 0 $\mu \mathrm{g} / \mathrm{mL}$ to $20000 \mu \mathrm{g} / \mathrm{mL}$ ) were added to the wells and incubated for 1,3 and 7 days. At the end of each incubation period, the MTT solution $(5 \mathrm{mg} / \mathrm{mL})$ was added to the medium and the cells were further incubated for another $4 \mathrm{~h}$ at $37^{\circ} \mathrm{C}$. The MTT solution was replaced with $200 \mu \mathrm{L}$ of dimethyl sulfoxide (DMSO) for $30 \mathrm{~min}$. Then, the absorbance was measured at $570 \mathrm{~nm}$ using ELISA plate reader (Bio-Rad, Hercules, CA, USA). The cell viability percentage was calculated using the following formula: $(\%)=[100 \times$ (sample absorbance)/ (control absorbance)]. Each test was repeated for three times. Means of the data 
were calculated and the CPE concentrations of 0.8 and $2 \mu \mathrm{g} / \mathrm{mL}$ were selected based on the viability results and were compared to the control group.

\subsection{RNA isolation and Real time PCR (RT-PCR)}

Total RNA was extracted from E-ESCs, OMA-ESCs and C-ESCs after 7 days of exposure to CPE using the FavorPrep ${ }^{\mathrm{TM}}$ Blood/Cultured Cell Total RNA (Favorgen, Ping-Tung, Taiwan), based on its manufacturer's instructions. The obtained RNA quantity and quality were measured by the ratio of optical density of 260/280 nm using Nanodrop ${ }^{T \mathrm{TM}}$ spectrophotometer (Nanodrop; Thermo FisherScientific, Wilmington, DE, USA) and then was stored at $-80^{\circ} \mathrm{C}$ until cDNA synthesis. The cDNA synthesis was performed using RevertAid $^{\text {TM }}$ First Strand cDNA Synthesis kit (Thermo Fisher Scientific, Inc., Waltham, MA, USA), according to the manufacturer's protocols. The synthesized cDNA was used as a template for polymerase chain reaction (PCR) amplification. The expression levels of MMP-2, COX-2, HDAC-1, DNMT-1, DNMT-3A, and DNMT-3B were quantified by RT-PCR which was performed using the ABI Biosystems StepOne and the RealQ Plus 2x Master Mix Green (Ampliqon A/S, Odense, Denmark). Moreover, primers were designed based on the human DNA sequences, which were found in the gene bank Primer-BLAST online program (Ye et al. 2012) (Table 1). The housekeeping gene, TATA-binding protein (TBP) was used as a reference to normalize the expression values. The following quantitative-PCR conditions were used: $10 \mathrm{~min}$ at $94^{\circ} \mathrm{C}$ followed by 40 cycles of $15 \mathrm{sec}$ at $94^{\circ} \mathrm{C}, 60 \mathrm{sec}$ at $60^{\circ} \mathrm{C}$ and finally melt curve stage was done to determine the specificity of the product. Additionally, for the confirmation of the results, Real Time-PCR products were measured on $2 \%$ ultra-pure agarose gel electrophoresis (Sigma, USA) according to the manufacturer's procedure.

\subsection{Western blot analysis}

Western blot analysis was done in accordance with standard procedures demonstrated in previous studies with slight modifications (Zhang et al. 2010). Based on the findings of cell MTT cell viability and proliferation assay, the most effective concentrations of the extracts, 0.8 and $2 \mu \mathrm{g} / \mathrm{mL}$, were selected and used for western blot analysis. In detail, the E-ESCs, OMA-ESCs and C-ESCs were treated with extracts and after $72 \mathrm{~h}$, cells were lysed by RIPA buffer (including: $50 \mathrm{mM}$ Tris- $\mathrm{HCl}(\mathrm{pH}=8.0), 0.4 \%$ Nonidet P-40, 120 $\mathrm{mM} \mathrm{NaCl}, 1.5 \mathrm{mM} \mathrm{MgCl} 2,2 \mathrm{mM}$ phenylmethylsulfonyl fluoride, $80 \mu \mathrm{g} / \mathrm{mL}$ leupeptin, $3 \mathrm{mM} \mathrm{NaF}$, and $1 \mathrm{mM}$ DTT) at $4^{\circ} \mathrm{C}$ for $20 \mathrm{~min}$. After that, the lysed components were undergone centrifugation at $12000 \times \mathrm{g}$ for $20 \mathrm{~min}$ at $4^{\circ} \mathrm{C}$. Then, Bradford protein assay was used in order to measure protein content of the solution. After the proteins were transferred to microporous polyvinylidene difluoride membrane (Millipore, France), the membranes were incubated in 5\% BSA (Sigma, USA) as a blocking buffer for $1 \mathrm{~h}$ at room temperature. At the next step, incubation of the membranes with primary antibodies was performed at $4^{\circ} \mathrm{C}$ overnight. In details, the samples were immunoblotted (1:200) with anti-B-actin, anti-MMP-2, anti-COX-2, anti-HDAC-1, anti-DNMT-1, anti-DNMT-3A, and anti-DNMT-3B (Cell Signaling Technology, Danvers, MA). Tween buffer was used to wash the membranes 3 times (10 min each) and after the washing process, the membranes were incubated with HRP-conjugated goat anti-mouse or rabbit secondary antibodies. The excess antibodies of the membranes were removed through 4 times of wash. Then, according to the 
manufacturer's catalog protocol of the kit, HRP activities were detected by ECL Plus Chemiluminescence Reagent (Amersham, Chalfont, UK).

\subsection{Computational details}

\subsubsection{Ligand and Receptor preparation}

Sixty-two compounds, detected in the $\mathrm{CPE}$, and six proteins were chosen for docking process. The PubChem databases of the Protein Database Bank (PDB) was used as the source of the threedimensional (3D) structure of ligands and receptors, respectively. Downloaded receptors include COX-2, MMP2, DNMT3B, DNMT1, DNMT3A and HDAC1 with PDB code of 3nt1, 3ayu, 3flg, 3os5, 4qbs, and 4bkx. The geometry of ligands was optimized using the HyperChem software version 8.0.10. Preparation of receptors including removing all non-standard residues, water and original hydrogens, and the addition of polar hydrogen, charges and bond orders, was performed using Chimera 1.15. Lastly, the format of all outputs was changed over to the suitable format for the docking process.

\subsubsection{Generation of grid}

The generation of the grid box is an important step in the docking process. Grid boxes with spacing of $0.375 \AA$ were generated using AUTOGRID, at the position of the active site of each receptor, which was selected based on the calculation of CASTp.

\subsubsection{Study of target proteins-marine derived compounds interactions}

Autodock Vina 1.1.2 was used to conduct the docking process to investigate interactions of target receptors and selected ligands. After completing the docking process, it provided different conformations. The conformation with the lowest binding affinity and RMSD $\leq 2 \AA$ was selected as the best one.

\subsection{Statistical analysis}

All statistical analyses were performed using IBM SPSS Statistics 26 software (SPSS for Windows, version 26, SPSS Inc, Chicago, Illinois, USA). Results were presented as the means \pm standard error of mean (SEM). Differences between groups were evaluated using the nonparametric Kruskal-Wallis test followed by the Dunn's test. $p$-value $\leq 0.05$ was considered statistically significant. All of the figures prepared with Graph pad prism software (v7.0a, GraphPad Software, Inc., San Diego, CA, USA) except for the Fig. 1.

\section{Results}

\subsection{Identification of ESCs}

The endometrial stem cells in control group (C-ESCs) were plastic adherent cells which showed spindleshaped, fibroblast-like morphology with radical or helical growth patterns. E-ESCs and OMA-ESCs isolated 
from different patients also presented with typical spindle-shaped and fibroblast-like morphological features. (figure.1).

The results showed that the human endometrial stem cells in three groups were positive for the standard mesenchymal markers CD73 and CD90 and negative for the hematopoietic marker CD 45 and endothelial marker CD34 or CD31. Therefore, the surface antigen marker of the endometrial cell culture revealed relatively homogenous cell population free from contaminant cells.

After culturing the C-ESCs, E-ESCs and OMA-ESCs in osteogenic and adipogenic media for 4 and 3 weeks, respectively; they were positive for both Alizarin Red S and Oil Red $O$ staining. The red brilliant stain in the culture plate showed the deposition of calcium by ESCs differentiated into osteoblast. The lipid droplet appeared in the cytoplasm of ESCs, which confirmed the multipotent capacity of ESCs (Fig. 1).

\subsection{Total phenolic content}

Considering that polyphenols are one of the important constituents of the hydrochloric extract of $C$. siliqua, TPC evaluation was performed by using Folin-Ciocalteu $(\mathrm{F}-\mathrm{C})$ assay. Results revealed the presence of $18.13 \pm 2.47 \mathrm{mg}$ pure phenol in $1 \mathrm{~g}$ of the dry extract.

\subsection{GC-MS profile of the CPE showed anti-cancer and anti- inflammatory compounds}

Several compounds with different biological activities were observed in GC-MS profile of CPE (Figure S1). In detail, sixty compounds were identified in the extract, four of which had anticancer biological activities based on previous studies (Table S1). Moreover, four compounds had cytotoxic effects and another four showed antioxidant properties in accordance with previous studies (Table S1). In addition, six of the CPE compounds had anti-inflammatory biological effects which are demonstrated in table S1. Other biological activities were also observed in the compounds of the extract including antimicrobial, antiseptic, and muscle relaxant effects based on previous studies.

\subsection{DPPH free radical scavenging activity decreased in CPE}

The antioxidant potency and reduction capability of DPPH radicals were determined by reduction in absorbance at $517 \mathrm{~nm}$ induced by antioxidants. The high antioxidant capacity was reported for the CPE with an $\mathrm{IC}_{50}$ value of $\mathrm{IC}_{50}=0.63 \pm 0.11 \mathrm{mgr} / \mathrm{mL}$ compared to quercetin as positive control which showed an $\mathrm{IC}_{50}$ value of $4.62 \pm 2.26 \mu \mathrm{M}$.

\subsection{Some concentrations of CPE decreased cell proliferation and viability of ESCs at MTT assay}

The cell viability percentages of ESCs exposed to various concentrations of CPE after 1, 3 and 7 days were repeated for three times and the mean values were calculated. CPE concentrations of higher than 2 
$\mu \mathrm{g} / \mathrm{mL}$ did not have acceptable ESCs viability after 7 days and were excluded. ESCs' viability in CPE concentrations of less than $2 \mu \mathrm{g} / \mathrm{mL}$ were not significantly different. Thus, the concentrations of 2 and $0.8 \mu \mathrm{g} / \mathrm{mL}$ were selected based on the proliferation and viability results for the following gene studies (Table 2). Kruskal-Wallis test followed by the Dunn's test showed a statistically significant decrese in proliferation and viability between 2 and $0.8 \mu \mathrm{g} / \mathrm{mL}$ concentrations in C-ESCs as compared to the untreated $(0 \mu \mathrm{g} / \mathrm{mL})$ group (Table 2$)$.

\subsection{Gene expression analysis}

Total RNA from E-ESCs, OMA-ESMs, and C-ESMs was extracted after 7 days of exposure to CPE, CDNA synthesis was performed and quantitative-PCR and gene expression levels were calculated. The gene expression levels at CPE concentrations of $0.8 \mu \mathrm{g} / \mathrm{mL}$ and $2 \mu \mathrm{g} / \mathrm{mL}$ were compared to the control group. The results are presented in Tables 3 and 4.

Treatment with $0.8 \mu \mathrm{g} / \mathrm{mL}$ of CPE significantly reduced the MMP-2 gene expression in OMA-ESCs $(p=$ $0.022)$ but the differences were not statistically significant $(p>0.05)$ for E-ESCs and C-ESCs as shown in Tables 3 and 4 and Fig. 2a. COX-2 gene expression was significantly downregulated in E-ESCs and upregulated in C-ESCs after treatment with 0.8 and $2 \mu \mathrm{g} / \mathrm{mL}$ of CPE, respectively $(p=0.022$ and $p=0.022)$ (Tables 3 and 4 and Fig. 2b).

The gene expression of HDAC-1 was significantly lowered in E-ESCs after treatment with $2 \mu \mathrm{g} / \mathrm{mL}$ of CPE $(p=0.022)$. Although HDAC-1 gene expression was decreased after CPE treatment with both concentrations in OMA-ESCs but the figures did not show statistically significant differences from the control group ( $p>0.05$ ) (Tables 3 and 4 and Fig. $2 c$ ). When compared to the control group, DNMT-1 gene expression was decreased after treatment with 0.8 and $2 \mu \mathrm{g} / \mathrm{mL}$ CPE in C-ESCs and OMA-ESCs. However, the numbers did not show any statistical significance ( $p>0.05)$ (Tables 3 and 4 and Fig. 3a).

DNMT-3A gene expression significantly increased by $2 \mu \mathrm{g} / \mathrm{mL}$ concentration of CPE in C-ESCs $(p=0.034)$. However, the gene expression after treatment with E-ESCs and OMA-ESCs was comparable to the control group (Tables 3 and 4 and Fig. 3b).

Treatment with $0.8 \mu \mathrm{g} / \mathrm{mL}$ of CPE reduced DNMT-3B gene expression in OMA-ESCs $(p=0.034)$. However, treatment with $2 \mu \mathrm{g} / \mathrm{mL}$ of CPE had no significant effect on DNMT-3B gene expression (Tables 3 and 4 and Fig. 3c).

\subsection{Western blot analysis demonstrated that the related antibodies decreased in E-ESCs, OMA-ESCs and C-ESCs after treatment with CPE}


Expression of the COX-2, HDAC-1, DNMT-1, DNMT-3A, and DNMT-3B decreased in E-ESCs, OMA-ESCs and C-ESCs after treatment with 0.8 and $2 \mu \mathrm{g} / \mathrm{mL}$ concentrations of the CPE (Fig. 3). Moreover, expression of the MMP-2 was also decreased in OMA-ESCs but this result was not observed in E-ESCs and C-ESCs. In EESCs and C-ESCs treatments, the MMP-2 expression increased (Fig. 3).

\subsection{Fourteen bioactive molecules in CPE had the highest affinity to anti-inflammatory and anticancer peptides}

The GC-MS analysis of the CPE resulted in fourteen compounds whose interactions with six target proteins were investigated through the docking process. The docking process resulted in several possible conformations for each ligand-protein complex. The best conformation or the most stable complex had the lowest binding affinity, $\Delta \mathrm{G}$ [U total in $\mathrm{kcal} / \mathrm{mol}]$. The results of the docking process have been listed in Table 3. The binding affinity of the selected conformation is in the range of -3.6 to $-7.8 \mathrm{Kcal} / \mathrm{mol}$.

Diphenyl sulfone; 3,4-dihydro-2(1H)-isoquinolinecarboximidamide; methanone, (1-

hydroxycyclohexyl)phenyl; and 4-imidazolidinone,1-benzoyl-2-(1-methylethyl)-3-methyl had the highest affinity to COX-2 with $\Delta \mathrm{G}$ of $-7.4,-7.3,-7.2$, and $-7.1 \mathrm{Kcal} / \mathrm{mol}$, respectively. 4-Imidazolidinone,1-benzoyl-2(1-methylethyl)-3-methyl; benzene,1,3,5-tris(1-methylpropyl)-; 3.4-dihydro-2(1H)-

Isoquinolinecarboximidamide; naphthalene,1,2,3,4-tetrahydro-1-isopropyl-1,2,4,4,7-pentamethyl-; naphthalene,decahydro-2,3-dimethyl-; benzoic acid, 4-heptyl-, 4-cyanophenyl ester; and methanone, (1hydroxycyclohexyl)phenyl- indicated the highest affinity to DNMT3A with $\triangle \mathrm{G}$ of $-5.8,-5.6,-5.5,-5.4,-5.4$, -5.4 , and - $5.4 \mathrm{Kcal} / \mathrm{mol}$. Diphenyl sulfone; Methanone, (1-hydroxycyclohexyl)phenyl-; 3.4-dihydro-2(1H)Isoquinolinecarboximidamide; and 4-imidazolidinone,1-benzoyl-2-(1-methylethyl)-3-methyl showed the highest affinity to MMP2 with $\Delta \mathrm{G}$ of $-6.8,-6.7,-6.6$, and $-6.6 \mathrm{Kcal} / \mathrm{mol}$. The best affinity to HDAC1 was observed for benzoic acid, 4-heptyl-,4-cyanophenyl ester with $\Delta \mathrm{G}$ of $-6 \mathrm{Kcal} / \mathrm{mol}$. The highest affinity to DNMT1 was related to naphthalene,1,2,3,4-tetrahydro-1-isopropyl-1,2,4,4,7-pentamethyl- with $\Delta \mathrm{G}$ of -7.8 $\mathrm{Kcal} / \mathrm{mol}$. Pentanoic acid, octyl ester; hexadecane; 2-methyl-5-(1-methylethenyl)-2-cyclohexen-1-ol; diethyleneglycol dimethacrylate; naphthalene; 9-octadecenoic acid (Z)-, methyl ester; and naphthalene,decahydro-2,3-dimethyl-; showed the highest affinity to DNMT3B with $\Delta \mathrm{G}$ of $-7.5,-7.4,-7.4$, $-7.2,-7.2,-7.1$, and $-7.1 \mathrm{Kcal} / \mathrm{mol}$, respectively. The intermolecular interactions of these compounds are depicted in Figs. 4A-4X.

\section{Discussion}

\subsection{CPE have anticancer and anti-inflammatory compounds}

The CPE showed 60 bioactive compounds, with anticancer (4compounds), cytotoxic (4compounds) and anti-inflammatory (6 compounds) properties (Table S1). The desirable compounds in the current study were those with anticancer and anti-inflammatory properties. Some compounds such as Octacosane, 9Octadecenoic acid (Z)-, methyl ester, Phenol, 2,4-bis(1,1-dimethylethyl)-, and Naphthalene have shown potent biological anticancer effects in previous studies (Belakhdar et al. 2015; Lim et al. 2020; Mallikarjunaswamy and Noushad 2021; Sianipar and Purnamaningsih 2018). Moreover, the 
phytochemical profile of the CPE has shown high amounts of phenolic content. Taken together, the GCMS and phytochemical profiles of the CPE demonstrated its potential anticancer effects. In line with the current study, former studies have reported high amounts of phenolic content and anticancer properties in the $C$. siliqua extract (Amessis-Ouchemoukh et al. 2017; Youssef et al. 2013). Moreover, we found antiinflammatory effects in six compounds of the extract as depicted in table S1, which agrees with similar results provided in previous studies on $C$. siliqua alcoholic extracts and the reported anti-inflammatory (Lachkar et al. 2016; Rtibi et al. 2017), as well as antioxidant, cell cytotoxic, antimicrobial properties of CPE (Lachkar et al. 2016; Rtibi et al. 2017).

\subsection{Ethanol extract of $C$. siliqua mitigated cell inflammatory pathway}

The ideal medical treatment for endometriosis has yet to be identified, and current medications are often accompanied by relatively short-term effects. Besides, these hormonal drugs have many undesirable side effects and can induce an amenorrhoeic state through developing a hypo-estrogenic environment (Zhao et al. 2015). Hence, finding novel treating agents remains necessary for improving fertility and other complications of endometriosis. The current study evaluated the impact of CPE on expression of genes related to invasion and attachment (MMP-2), inflammation (COX-2) and epigenetic mechanisms (DNMTs and HDAC-1) involved in endometriosis.

Uncontrolled regeneration of free radicals is a critical contributor to aging via attacking various biomolecules, membrane, lipids, proteins, enzymes, and DNA which leads to oxidative stress and ultimately cell death. In case of infertility, overproduction of free radicals and oxidative damage can lead to compromised follicles in endometriosis-associated fecundity impairment (Lin et al. 2020; Sen and Chakraborty 2011). Antioxidants are stable components which donate an electron or hydrogen to counteract the effect of free radicals and terminate the chain reaction before molecules are damaged. Also, the radical scavenging property of antioxidants delays or inhibits cellular damage. Phenolic compounds are regarded as powerful molecules with a high potential to neutralize free radicals (Gulcin 2020; Kurutas 2016; Lobo et al. 2010). In this study, TPC analysis confirmed presence of phenolic antioxidants in $C$. siliqua, which may be responsible for its therapeutic effects. Also, the hydroalcoholic extract of $C$. siliqua was screened for its in vitro antioxidant activity and exhibited promising antioxidant potency. Phytochemical analysis proposes natural antioxidants as a promising novel therapy to reduce the endometriosis-associated infertility rate (Lin et al. 2020). Biological activities and pharmacological properties of $C$. siliqua may be linked to its high phenolic content especially gallic acid, catechin, epicatechingallate, epigallocatechingallate, and quercetin glycosides (Oziyci et al. 2014; Rtibi et al. 2017). Also, biometal co-factors including $\mathrm{Cu}, \mathrm{Fe}, \mathrm{Mn}$ and $\mathrm{Zn}$ which are essential for antioxidant enzymes are found in C. silique (Soleimanzadeh et al. 2020).

In the present study, total RNA was extracted from E-ESCs, OMA-ESMs, and C-ESMs after exposure to CPE. After CDNA synthesis and quantitative-PCR, gene expression levels were calculated. The gene expression levels at CPE concentrations of $0.8 \mu \mathrm{g} / \mathrm{mL}$ and $2 \mu \mathrm{g} / \mathrm{mL}$ were compared to that of the control 
group. Our data demonstrated that treatment of E-ESCs with CPE suppressed the expression of COX-2 gene. Previous studies have suggested that COX-2 over expression plays a crucial role in not only endometriosis-associated pain but also in the pathogenesis and development of the disease through the marked enhancement of inflammatory mediators (Buchweitz et al. 2006; Lai et al. 2019). Moreover, the protein expression of E-ESCs, OMA-ESMs, and C-ESMs was evaluated after cell treatment with $0.8 \mu \mathrm{g} / \mathrm{mL}$ and $2 \mu \mathrm{g} / \mathrm{mL}$ of CPE concentrations. The COX-2 protein expression decreased after treatment with both concentrations, compared to control group.

Endometriosis is an inflammatory disease associated with various alterations of immune cells and inflammatory cytokines. This subclinical inflammation is mainly responsible for the disease-associated pain and infertility (Bina et al. 2019). Flavonoids and tannins, as main phenolic compounds found in $C$. siliqua, are known to have anti-inflammatory activities by inhibiting the expression of inflammatory mediators, such as cytokines, inducible nitric-oxide synthase (iNOS), and COX-2 (Rtibi et al. 2016). Since elevated expression of COX-2 in both endometrial and endometriotic cells of women with endometriosis plays critical role in pathogenesis of pain and infertility (Koukoura et al. 2016), its down-regulation by $\mathrm{CPE}$ may reduce the disease-associated pain and improve the fertility outcome. Further in-vivo studies are required to investigate these clinical applications of CPE in endometriosis.

\subsection{Ethanol extract of $C$. siliqua reduced epigenetic factors of endometriosis}

A growing body of evidence over the recent years suggest that endometriosis is an epigenetic disorder (Koukoura et al. 2016). Epigenetic is defined as "heritable and reversible changes in gene expression" with no changes in the DNA sequence (Lu et al. 2006). Two predominant epigenetic mechanisms are DNA methylation, occurring through DNMTs, and histone modification by HDACs (Colon-Diaz et al. 2012; Koukoura et al. 2016). In line with previous studies (Szczepanska et al. 2013; Szczepanska et al. 2012), we observed an increased level of DNMT3A expression in E-ESCs from women with endometriosis in comparison with women in the control group. However, as reported previously, the role of other DNMTs in the pathogenesis of endometriosis is still controversial (Szczepanska et al. 2013). Results of the current study reveal that DNMT-3B gene expression levels can be significantly reduced after treatment with 0.8 $\mu \mathrm{g} / \mathrm{mL}$ of CPE. However, gene expression of HDAC-1 was only reduced in CPE-treated E-ESCs after exposure to $2 \mu \mathrm{g} / \mathrm{mL}$ of CPE and no significant efficacy of CPE was seen in terms of reducing HDAC-1 gene expression in OMA-ESCs. Moreover, the western blot analysis showed the DNMT-3A and - 3B proteins expression were decreased in all three cell types after treatment with 0.8 and $2 \mu \mathrm{g} / \mathrm{mL}$ of $\mathrm{CPE}$. In addition, the HDAC-1 protein expression also showed a decline after treatment with both concentrations. However, in contrast with gene expression, the reduction in protein expression of DNMT-3B and HDAC-1 was higher after exposure to $2 \mu \mathrm{g} / \mathrm{mL}$ than $0.8 \mu \mathrm{g} / \mathrm{mL}$ of CPE. In this regard, HDAC inhibitors have been suggested as attractive treatment targets for endometriosis in recent years. In-vitro and in-vivo studies using human endometrial stromal and epithelial cells and animal models of endometriosis, respectively treated with different HDAC inhibitors, have shown anti-proliferative activities and reducing impacts on the lesion size (Liu et al. 2012; Wu and Guo 2008). 


\subsection{Ethanol extract of $C$. siliqua decreased MMP-2 expression as a metastatic associated enzyme}

MMP-2 acts as a key enzyme associated with tumor metastasis through degradation of extracellular matrix components (Iurlaro et al. 1999). MMPs are essential enzymes in the ectopic implantation of endometrial tissue, and our study revealed that the MMP-2 gene expression level in OMA-ESCs could be modulated by $0.8 \mu \mathrm{g} / \mathrm{mL}$ of CPE. Moreover, the protein expression of MMP-2 was also decreased in OMAESCs. This downregulation of MMP-2 protein expression was not observed in C-ESCs and E-ESCs. Since this study claims the effectiveness of $C$. siliqua in treatment of endometriosis based on in-vitro results, further well-designed animal and human trials are recommended to achieve conclusive results on the efficacy and safety of this natural product in endometriosis. Two noteworthy limitations of our study were limited sample size and lack of budget to carry out further in vivo evaluations. Moreover, the antioxidative and anti-inflammatory effects of $C$. siliqua have been evaluated recently, but further biochemical studies are necessary to assess parameters inducing these effects in our study.

Computational study showed not only one specific compound had the highest affinity to different proteins and it is not possible to introduce a specific compound as a most effective compound. A combination of several compounds can be involved in inhibition of proteins. This difference can be attributed to the role of conformation and intermolecular interactions in the formation the ligand-protein complex (Pagadala et al. 2017). According to the docking scores, 14 of 60 studied compounds showed good affinity to different proteins. However, among them, three compounds including 3,4-dihydro-2(1H)isoquinolinecarboximidamide, 4-imidazolidinone,1-benzoyl-2-(1-methylethyl)-3-methyl, and methanone (1hydroxycyclohexyl)phenyl- showed good affinity to three proteins. As observed in Figs. 1-6, different interactions containing hydrogen bonds, van der Waals interactions, and hydrophobic interactions play in the binding of compounds to proteins. Therefore, it can be inferred that the inhibitory effect of CPE is mostly related to these compounds.

\section{Conclusions}

C. siliqua may serve as a novel therapy for endometriosis by regulating inflammation and epigenetics, mediated through down-regulating cell inflammatory pathway, metastatic associated enzymes, and epigenetic factors of endometriosis expression.

\section{Declarations}

\section{Ethics approval and consent to participate}

The study was approved by the Institutional Review Board and related Ethics Committee of Shiraz University of Medical Sciences (Ethics code: IR.SUMS.REC.1397.555). After thorough explanation of the study design, informed consents were obtained from all of the participants and donors prior to sample collection. 


\section{Consent for publication}

Not applicable.

\section{Availability of data and material}

Datasets related to this project can be obtained from corresponding author based on a reasonable request.

\section{Funding}

The results presented in this paper were part of a student thesis (thesis number: 97.01.01.18000) for a degree of Obstetrics and Gynecology. This study was financially supported by Infertility Research Center, Shiraz University of Medical Sciences, Shiraz, Iran.

\section{Competing interests}

The authors declare no conflicts of interest.

\section{Authors' contributions}

A. T., Z. K., and B. N. J. conceived and designed the format of the manuscript. A. H., A. A., N. B., K. H., G. M., A. B., I. J., S. Z., P. B., A. I., T. P., and A. K. collected the data, and drafted and edited the manuscript. A. T., N. B, A. A., and Z. K. computational and statistical analysis. N. B., A. T., Z. K., and A. A. drew the Figures and Tables. All the authors reviewed the manuscript and all of them contributed to the critical reading and discussion of the manuscript. All authors have read and agreed to the published version of the manuscript.

\section{Acknowledgments}

Not applicable.

\section{References}

1. Amessis-Ouchemoukh $\mathrm{N}$ et al. (2017) Bioactive metabolites involved in the antioxidant, anticancer and anticalpain activities of Ficus carica L., Ceratonia siliqua L. and Quercus ilex L. extracts. Ind Crops Prod 95:1-12

2. Ardakani Movaghati MR, Yousefi M, Saghebi SA, Sadeghi Vazin M, Iraji A, Mosavat SH (2019) Efficacy of black seed (Nigella sativa L.) on kidney stone dissolution: A randomized, double-blind, 
placebo-controlled, clinical trial. Phytother Res 33:1404-1412

3. Belakhdar G, Benjouad A, Abdennebi E (2015) Determination of some bioactive chemical constituents from Thesium humile Vahl. J Mater Environ Sci 6:1-6

4. Bina F, Soleymani S, Toliat T, Hajimahmoodi M, Tabarrai M, Abdollahi M, Rahimi R (2019) Plantderived medicines for treatment of endometriosis: A comprehensive review of molecular mechanisms. Pharmacol Res 139:76-90

5. Buchweitz O, Staebler A, Wulfing P, Hauzman E, Greb R, Kiesel L (2006) COX-2 overexpression in peritoneal lesions is correlated with nonmenstrual chronic pelvic pain. Eur J Obstet Gynecol Reprod Biol 124:216-221

6. Canis M, Donnez JG, Guzick DS, Halme JK, Rock JA, Schenken RS, Vernon MW (1997) Revised american society for reproductive medicine classification of endometriosis: 1996. Fertil Steril 67:817821

7. Chung HW, Lee JY, Moon H-S, Hur SE, Park MH, Wen Y, Polan ML (2002) Matrix metalloproteinase-2, membranous type 1 matrix metalloproteinase, and tissue inhibitor of metalloproteinase-2 expression in ectopic and eutopic endometrium. Fertility and sterility 78:787-795

8. Colon-Diaz M et al. (2012) HDAC1 and HDAC2 are differentially expressed in endometriosis. Reprod Sci 19:483-492

9. Custódio L et al. (2011) In vitro cytotoxic effects and apoptosis induction by a methanol leaf extract of carob tree (Ceratonia siliqua L.). J Med Plant Res 5:1987-1996

10. Custódio L et al. (2013) Sapwood of carob tree (Ceratonia siliqua L.) as a potential source of bioactive compounds. Rec Nat Prod 7:225-229

11. Fata S, Tokat MA, Bagardi N, Yilmaz B (2019) The traditional practices used by couples with fertility problems, affecting factors, expected benefits, and learning paths: The Turkey Sample. Niger J Clin Pract 22:806-811

12. Fernandez-Shaw S, Shorter SC, Naish CE, Barlow DH, Starkey PM (1992) Isolation and purification of human endometrial stromal and glandular cells using immunomagnetic microspheres. Hum Reprod 7:156-161

13. Goulas V, Stylos E, Chatziathanasiadou MV, Mavromoustakos T, Tzakos AG (2016) Functional components of carob fruit: linking the chemical and biological space. Int J Mol Sci 17:1875

14. Gulcin I (2020) Antioxidants and antioxidant methods: an updated overview. Arch Toxicol 94:651-715

15. Guo SW (2009) Epigenetics of endometriosis. Mol Hum Reprod 15:587-607

16. Huang H-F, Hong L-H, Tan Y, Sheng J-Z (2004) Matrix metalloproteinase 2 is associated with changes in steroid hormones in the sera and peritoneal fluid of patients with endometriosis. Fertil Steril $81: 1235-1239$

17. Iurlaro $\mathrm{M}$ et al. (1999) Angiogenesis extent and expression of matrix metalloproteinase-2 and -9 correlate with upgrading and myometrial invasion in endometrial carcinoma. Eur J Clin Invest 29:793-801 
18. Koohi-Hosseinabadi 0 et al. (2017) Biochemical, hematological, and pathological related healing effects of Elaeagnus angustifolia hydroalcoholic extract in 5-fluorouracil-induced oral mucositis in male golden hamster. Environ Sci Pollut Res Int 24:24447-24453

19. Koukoura O, Sifakis S, Spandidos DA (2016) DNA methylation in endometriosis (Review). Mol Med Rep 13:2939-2948

20. Kurutas EB (2016) The importance of antioxidants which play the role in cellular response against oxidative/nitrosative stress: current state. Nutr J 15:71

21. Lachkar N, Al-Sobarry M, El Hajaji H, Lamkinsi T, Lachkar M, Cherrah Y, Alaoui K (2016) Antiinflammatory and antioxidant effect of Ceratonia siliqua L. methanol barks extract. J Chem Pharm Res 8:202-210

22. Lai ZZ et al. (2019) Cyclooxygenase-2 in endometriosis. Int J Biol Sci 15:2783-2797

23. Lim YH, Oo CW, Koh RY, Voon GL, Yew MY, Yam MF, Loh YC (2020) Synthesis, characterization, and anti-cancer activity of new chalcone derivatives containing naphthalene and fluorine moieties. Drug Dev Res 81:1-10

24. Lin X et al. (2020) Excessive oxidative stress in cumulus granulosa cells induced cell senescence contributes to endometriosis-associated infertility. Redox Biol 30:101431

25. Liu M, Liu X, Zhang Y, Guo SW (2012) Valproic acid and progestin inhibit lesion growth and reduce hyperalgesia in experimentally induced endometriosis in rats. Reprod Sci 19:360-373

26. Lobo V, Patil A, Phatak A, Chandra N (2010) Free radicals, antioxidants and functional foods: Impact on human health. Pharmacogn Rev 4:118-126

27. Lu Q, Qiu X, Hu N, Wen H, Su Y, Richardson B (2006) Epigenetics, disease, and therapeutic interventions. Ageing Res Rev 5:449-467

28. Mallikarjunaswamy G, Noushad N (2021) Probiotic rhizospheric Bacillus sp. from Zingiber officinale Rosc. displays antifungal activity against soft rot pathogen Pythium sp. Current Plant Biology 27:100217

29. Mobli M, Qaraaty M, Amin G, Haririan I, Hajimahmoodi M, Rahimi R (2015) Scientific evaluation of medicinal plants used for the treatment of abnormal uterine bleeding by Avicenna. Arch Gynecol Obstet 292:21-35

30. Ostovar M et al. (2020) Effects of Citrullus colocynthis L. in a rat model of diabetic neuropathy. J Integr Med 18:59-67

31. Oziyci HR et al. (2014) Mineral composition of pods and seeds of wild and grafted carob (Ceratonia siliqua L.) fruits. Sci Hortic 167:149-152

32. Pagadala NS, Syed K, Tuszynski J (2017) Software for molecular docking: a review. Biophys Rev 9:91-102

33. Parasar P, Ozcan P, Terry KL (2017) Endometriosis: epidemiology, diagnosis and clinical management. Curr Obstet Gynecol Rep 6:34-41 
34. Rtibi K et al. (2016) Preventive effect of carob (Ceratonia siliqua L.) in dextran sulfate sodiuminduced ulcerative colitis in rat. Rsc Advances 6:19992-20000

35. Rtibi K et al. (2017) Chemical constituents and pharmacological actions of carob pods and leaves (Ceratonia siliqua L.) on the gastrointestinal tract: A review. Biomed Pharmacother 93:522-528

36. Sen S, Chakraborty R (2011) The role of antioxidants in human health. In: Andreescu S (ed) Oxidative stress: diagnostics, prevention, and therapy. ACS Publications, pp 1-37

37. Sianipar NF, Purnamaningsih R (2018) Enhancement of the contents of anticancer bioactive compounds in mutant clones of rodent tuber (Typhonium flagelliforme Lodd.) based on GC-MS analysis. Pertanika J Trop Agric Sci 41:1-16

38. Soleimanzadeh A, Kian M, Moradi S, Mahmoudi S (2020) Carob (Ceratonia siliqua L.) fruit hydroalcoholic extract alleviates reproductive toxicity of lead in male mice: Evidence on sperm parameters, sex hormones, oxidative stress biomarkers and expression of Nrf2 and iNOS. Avicenna J Phytomed 10:35-49

39. Szczepanska M, Mostowska A, Wirstlein P, Malejczyk J, Ploski R, Skrzypczak J, Jagodzinski PP (2013) Polymorphic variants of DNMT3A and the risk of endometriosis. Eur J Obstet Gynecol Reprod Biol 166:81-85

40. Szczepanska M, Wirstlein P, Skrzypczak J, Jagodzinski PP (2012) Expression of HOXA11 in the midluteal endometrium from women with endometriosis-associated infertility. Reprod Biol Endocrinol 10:1

41. Tansaz M, Memarzadehzavareh H, Qaraaty M, Eftekhar T, Tabarrai M, Kamalinejad M (2016) Menorrhagia management in Iranian traditional medicine. J Evid Based Complementary Altern Med 21:71-76

42. Vignali M, Bianchi S, Candiani M, Spadaccini G, Oggioni G, Busacca M (2005) Surgical treatment of deep endometriosis and risk of recurrence. J Minim Invasive Gynecol 12:508-513

43. Wu Y, Guo SW (2008) Histone deacetylase inhibitors trichostatin A and valproic acid induce cell cycle arrest and p21 expression in immortalized human endometrial stromal cells. Eur J Obstet Gynecol Reprod Biol 137:198-203

44. Wu Y, Strawn E, Basir Z, Halverson G, Guo SW (2007) Aberrant expression of deoxyribonucleic acid methyltransferases DNMT1, DNMT3A, and DNMT3B in women with endometriosis. Fertil Steril 87:24-32

45. Xiaomeng X, Ming Z, Jiezhi M, Xiaoling F (2013) Aberrant histone acetylation and methylation levels in woman with endometriosis. Arch Gynecol Obstet 287:487-494

46. Yang $\mathrm{J}$ et al. (2011) Clinical significance of the expression of DNA methyltransferase proteins in gastric cancer. Mol Med Rep 4:1139-1143

47. Ye J, Coulouris G, Zaretskaya I, Cutcutache I, Rozen S, Madden TL (2012) Primer-BLAST: a tool to design target-specific primers for polymerase chain reaction. BMC Bioinform 13:134

48. Youssef MKE, El-Manfaloty MM, Ali HM (2013) Assessment of proximate chemical composition, nutritional status, fatty acid composition and phenolic compounds of carob (Ceratonia siliqua L.). 
Food Public Health 3:304-308

49. Zhang J-y et al. (2010) Anthracenedione derivatives as anticancer agents isolated from secondary metabolites of the mangrove endophytic fungi. Mar Drugs 8:1469-1481

50. Zhao $\mathrm{Y}$ et al. (2015) Dual suppression of estrogenic and inflammatory activities for targeting of endometriosis. Sci Transl Med 7:271ra279

\section{Tables}

\section{Table 1.}

Real-time PCR primers used for evaluation of anti-endometriotic effects of Ceratonia siliqua L. pod ethanol extract on DNA methyltransferase, histone deacetylase-1, matrix metalloproteinase-2 and cyclooxygenase-2 genes expression in endometrial stem cells isolated from women with endometriosisassociated infertility

\begin{tabular}{lll} 
Genes & Primer sequences & Sizes (base pair) \\
\hline TBP & Forward: 5'-GGATAAGAGAGCCACGAACCAC-3' & 139 \\
\hline MMP2 & Foverse: 5'-TTAGCTGGAAAACCCAACTTCTG-3' & \\
\hline & Reverse: 5'-TCTTCTTCACCTCATTGTATCTCC -3' & \\
\hline Cox-2 & Forward: 5'-CAAATTGCTGGCAGGGTTGC-3' & 139 \\
\hline & Reverse: 5'-AGGGCTTCAGCATAAAGCGT-3' & \\
\hline DNMT1 & Forward: 5'-GAGAGAGTGCCTCAGCTAAA -3' & 143 \\
\hline & Reverse: 5'-CATGTGAACGGACAGATTGAC -3' & \\
\hline DNMT3A & Forward: 5'-CACCGGCCATACGGTGG -3' & 118 \\
\hline DNMT3B & Forward: 5'-GCCCATTTGACTTGGTGATTG -3' & 92 \\
\hline HDAC1 & Forward: 5'-GTCCAAATGCAGGCGATTCC -3' & \\
\hline & Reverse: 5'-GAGCAGATCGAGATGCGCTTG-3' & \\
\hline
\end{tabular}




\section{Table 2.}

Mean \pm SD of cell viability of endometrial stem cells (ESCs) by MTT assay results in different Ceratonia siliqua L. pod extract (CPE) concentrations

\begin{tabular}{lllllll}
\multirow{2}{*}{ MTT day } & Cell & \multicolumn{5}{c}{ Cell viability in different concentrations of CPE $(\mu \mathrm{g} / \mathrm{mL})$} \\
\cline { 3 - 7 } & & 0 & 0.2 & 0.4 & 0.8 & 2 \\
\hline 1 & E-ESCs & $100 \pm 0$ & $92.2 \pm 11.2$ & $81.8 \pm 6.3$ & $86.5 \pm 5.4$ & $83.4 \pm 6.5$ \\
\cline { 2 - 7 } & OMA-ESCs & $100 \pm 0$ & $92.9 \pm 10.9$ & $85.7 \pm 7.5$ & $96.3 \pm 3.4$ & $93.6 \pm 12.5$ \\
\hline C-ESCs & $100 \pm 0$ & $123.5 \pm 12.3$ & $104.7 \pm 9.4$ & $98.0 \pm 5.4$ & $96.1 \pm 7.6$ \\
\hline 3 & E-ESCs & $100 \pm 0$ & $91.8 \pm 20.9$ & $86.3 \pm 15.1$ & $80.2 \pm 12.2$ & $83.2 \pm 6.0$ \\
\hline & OMA-ESCs & $100 \pm 0$ & $106.0 \pm 3.2$ & $99.5 \pm 5.5$ & $91.4 \pm 5.8$ & $96.2 \pm 3.0$ \\
\hline 7 & C-ESCs & $100 \pm 0$ & $116.1 \pm 31.2$ & $88.1 \pm 13.7$ & $94.5 \pm 13.4$ & $93.1 \pm 18.5$ \\
\hline & E-ESCs & $100 \pm 0$ & $80.4 \pm 5.8$ & $76.2 \pm 1.2$ & $79 \pm 6.3$ & $76.2 \pm 2.3$ \\
\hline & OMA-ESCs & $100 \pm 0$ & $86.8 \pm 6.9$ & $79.8 \pm 7.4$ & $74.1 \pm 14.7$ & $59.4 \pm 29.4$ \\
\hline & C-ESCs & $100 \pm 0^{\mathrm{a}, \mathrm{b}}$ & $88.1 \pm 4.4$ & $86.1 \pm 8.5$ & $77.2 \pm 5.9^{\mathrm{a}}$ & $76.9 \pm 5.8^{\mathrm{b}}$
\end{tabular}

a,b Statistical significance was seen $(\mathrm{P}<0.05)$. Abbreviations: C-ESCs, control- endometrial stem cells; $\mathrm{E}$ ESCs, endometriosis- endometrial stem cells; OMA-ESCs, endometrioma- endometrial stem cells.

\section{Table 3.}

The values of binding affinity $(\mathrm{Kcal} / \mathrm{mol})$ of ligands in Ceratonia siliqua L. pod extract to receptors 
Compounds

Binding affinity (Kcal/mol)

COX- DNMT3A MMP2 HDAC1 DNMT1 DNMT3B

2

(S)-2-Methyl-1-dodecanol

$-5.1$

$-3.9$

$-4.8$

$-4.4$

$-4.9$

$-5$

Naphthalene, 1,2,3,4-tetrahydro-1-

$-6.7 \quad-5.4$

$-5.7$

$-5.2$

$-7.8$

$-6.9$

isopropyl-1,2,4,4,7-pentamethyl-

1,2-Benzenedicarboxylic acid,

$-6.6 \quad-3.8$

$-5$

$-4.9$

$-5.7$

$-5.7$

diisooctyl ester

Naphthalene, decahydro-2,3-

$-6.9 \quad-5.4$

$-6.1$

$-4.9$

$-6.7$

$-7.1$

dimethyl-

1-Eicosanol

$-5.4 \quad-3.9$

$-5$

$-3.6$

$-5.4$

$-5$

1-Ethyl-3-methylbenzene

$-5.9 \quad-4.9$

$-5.1$

$-4.8$

$-5.9$

$-6.4$

1-Methoxy-2-propyl acetate

$-4.7 \quad-3.7$

$-4.1$

$-3.8$

$-4.3$

$-5.3$

2,6-Dimethyloctane

$-4.7 \quad-3.9$

$-4.6 \quad-4$

$-4.6$

$-4.8$

2-(Prop-2-enoyloxy)tetradecane

$-4.8 \quad-4.5$

$-4.5$

$-4.5$

$-5.1$

$-5.1$

2-Butyl-1-octanol

$-4.9 \quad-4.3$

$-4.9$

$-3.7$

$-5.1$

$-6.2$

2-Dodecanol

$-5.7 \quad-5.1$

$-5.4$

$-5$

$-5.7$

$-5.2$

2-Hexyl-1-octanol

$-5.2 \quad-4.1$

$-4.5$

$-4.4$

$-5.3$

$-6.7$

2-methyl-5-(1-methylethenyl)- 2-

Cyclohexen-1-ol

$-6.3 \quad-4.8$

$-5.7$

$-4.7$

$-5.8$

$-7.4$

3,4-dihydro-2(1H)-

isoquinolinecarboximidamide

$-7.3 \quad-5.5$

$-6.6$

$-5.3$

$-7.2$

$-5.2$

Heptan, 3-ethyl-2-methyl-

$-5.2 \quad-4$

$-4.7$

$-4.4$

$-5$

$-5.5$

3-Hexadecyloxycarbonyl-5-(2-

hydroxyethyl)-4-methylimidazolium

$-5.2 \quad-4$

$-5$

$-4.8$

$-6.5$

$-6.6$

ion

4-Imidazolidinone, 1-benzoyl-2-(1methylethyl)-3-methyl

4-Methyldecane

$-4.8 \quad-4$

$-4.5$

$-4$

$-5.4$

$-7.3$

$-5.3$

9,9-Dimethoxybicyclo[3.3.1]nona-

2,4-dione

$-5.5 \quad-4.8$

$-5.1$

$-4.5$

$-5$

$-6.1$

9-Octadecenoic acid (Z)-, methyl

$-4.5 \quad-3.9$

$-4.5$

$-4$

$-5.2$

$-7.1$

ester

Benzene, 1,3,5-tris(1-methylpropyl)-

$-6.6 \quad-5.6$

$-5.9$

$-5.3$

$-7$

$-6.7$

Benzene, 1,2,4,5-tetramethyl-

$-6.6 \quad-5.2$

$-5.4$

$-4.7$

$-6.6$

$-6.5$ 
Benzene, 1-methyl-4-(1-methylethyl) $\quad-6.4 \quad-5.1 \quad-5.4 \quad-4.5 \quad-6.4 \quad-6.4$

$\begin{array}{lllllll}\text { Benzene, 1-ethyl-2,3-dimethyl- } & -6.4 & -5 & -5.2 & -4.4 & -6.1 & -6\end{array}$

$\begin{array}{lllllll}\text { Benzoic acid, 4-heptyl-, 4- } & -6.5 & -5.4 & -6.2 & -6 & -6.8 & -6.3\end{array}$

cyanophenyl ester

$\begin{array}{lllllll}\begin{array}{l}\text { Cyclohexanone, 3-(4- } \\ \text { hydroxybutyl)-2-methyl- }\end{array} & -4.8 & -4.9 & -5.8 & -4.6 & -6.1 & -5.4\end{array}$

\begin{tabular}{lcccccc} 
Decane, 4-methyl- & -4.4 & -4 & -4.5 & -4.2 & -4.5 & -5.1 \\
\hline Decane & -4.8 & -3.8 & -4.3 & -3.8 & -4.6 & -5.3 \\
\hline $\begin{array}{l}\text { D-Glucose, cyclic 1,2-ethanediyl } \\
\text { mercaptal, pentaacetate }\end{array}$ & -5.5 & -4.5 & -4.5 & -4.9 & -5.7 & -4.7 \\
\hline Diethyleneglycol dimethacrylate & -5.8 & -4.6 & -5.3 & -4.5 & -5.6 & -7.2 \\
\hline Diphenyl sulfone & -7.4 & -5.3 & -6.8 & -5.5 & -7.2 & -4.8 \\
\hline Dodecane & -4.5 & -3.9 & -4.5 & -4.2 & -4.7 & -5 \\
\hline Dodecanol & -4.9 & -4.1 & -4.7 & -4 & -4.9 & -5.6 \\
\hline gamma-Thionodecalactone & -5.1 & -4.4 & -4.5 & -4.1 & -5.1 & -4.6 \\
\hline Heptacosane & -5.3 & -3.8 & -4 & -3.9 & -4.8 & -4.3 \\
\hline Hexadecane & -4.7 & -4 & -4.2 & -4 & -5 & -7.4 \\
\hline $\begin{array}{l}\text { Methanone, (1- } \\
\text { hydroxycyclohexyl)phenyl- }\end{array}$ & -7.2 & -5.4 & -6.7 & -5.3 & -7.2 & -5.1
\end{tabular}

$\begin{array}{lllllll}\text { Methoxyacetic acid, 3-tridecyl ester } & -5.2 & -4.2 & -4.7 & -4.7 & -5.4 & -4.5\end{array}$

$\begin{array}{lllllll}\text { Methoxyacetic acid, 2-tetradecyl } & -4.9 & -3.9 & -4.6 & -3.9 & -5.3 & -4.6\end{array}$

ester

$\begin{array}{lllllll}\text { Methoxyacetic acid, pentadecyl } & -5.3 & -4 & -5 & -4 & -5.3 & -4.7\end{array}$

ester

Methyl 3-hydroxytetradecanoate

$-5.5 \quad-4.3$

$-5.2$

$-4.5$

$-5.6$

$-7$

Naphtalene

$-6.7 \quad-5.1$

$-5.6$

$-4.5$

$-6.8$

$-7.2$

Naphthalene, decahydro-1,6-

dimethyl-

$-6.5 \quad-5.3$

$-5.9$

$-5.3$

$-6.9$

$-4.7$

n-Dodecyl acetate

$-5.2 \quad-4.1$

$-5.1$

$-4.4$

$-5.1$

$-5.3$

n-Hexadecanoic acid

$-4.4 \quad-4.3$

$-4.7$

$-4.3$

$-5.2$

$-4.4$

Nonadecane

$-4.4 \quad-3.7$

$-5.2$

$-3.8$

$-5$

$-4.5$

Octacosane

$-4.4 \quad-3.7$

$-3.7$

$-3.8$

$-4.9$

$-4.7$

Octadecane, 1-(ethenyloxy)-

$-5.4 \quad-3.7$

$-4.5$

$-4.1$

$-4.8$

$-4.4$ 


\begin{tabular}{lcccccc} 
Octadecane, 6-methyl- & -5.1 & -3.6 & -4.4 & -4 & -4.5 & -4.6 \\
\hline Octadecanoic acid, methyl ester & -5.3 & -4.3 & -4.3 & -4.5 & -5 & -5.1 \\
\hline Oxalic acid, allyl hexadecyl ester & -4.5 & -4.3 & -4.1 & -4.5 & -5.5 & -5.8 \\
\hline o-Xylene & -5.7 & -4.5 & -5 & -3.9 & -5.7 & -5.1 \\
\hline $\begin{array}{l}\text { Pentadecanoic acid, 14-methyl-, } \\
\text { methyl ester }\end{array}$ & -5.1 & -4.2 & -4.8 & -4 & -5.5 & -4.4 \\
\hline Pentanoic acid, octyl ester & -5.5 & -4.1 & -4.4 & -4.3 & -4.8 & -7.5 \\
\hline Phenol, 2,4-bis(1,1-dimethylethyl)- & -6.8 & -5.1 & -5.8 & -4.8 & -7.3 & -4.5 \\
\hline $\begin{array}{l}\text { Sulfurous acid, 2-ethylhexyl nonyl } \\
\text { ester }\end{array}$ & -5.1 & -4.5 & -4.5 & -4 & -5 & -4.8 \\
\hline Tetracosane & -4.9 & -3.8 & -4.4 & -3.9 & -4.7 & -4.7 \\
\hline Tetradecane & -5.4 & -4 & -4.2 & -3.7 & -4.8 & -6.6 \\
\hline Tridecane, 3-methyl- & -5.6 & -5.1 & -5.3 & -5.1 & -6.1 & -4.8 \\
\hline Tridecane & -4.6 & -3.8 & -4.4 & -3.6 & -4.2 & -4.7 \\
\hline Undecanal & -4.6 & -3.8 & -4.6 & -4.1 & -4.6 & -4.9 \\
\hline Undecane & -4.6 & -3.8 & -4.4 & -4.1 & -4.7 & -5
\end{tabular}

\section{Figures}

\section{Figure 1}

Cell surface marker and differentiation tests for confirmation of endometrial stem cells (ESCs). a) Flow cytometry analyses for ESCs were derived from endometrium of endometrioma patients (OMA-ESCs) and deep infiltrative endometriosis samples of women with endometriosis associated infertility (E-ESCs) and ESCs derived from endometrium of endometriosis free, normal women (C-ESCs) were positive for CD90 and CD73 marker but the expression of CD45, CD31 and CD34 were negative. b) Oil Red 0 revealed the presence of lipid droplets in the cells cultured in adipogenic medium. The cell cultured in osteogenic medium showed $\mathrm{Ca}^{2+}$ deposition after staining in alizarin $\mathrm{Red} / \mathrm{S}$. 
Relative mRNA expression level (Mean \pm SD) of matrix metalloproteinase-2 (MMP-2), cyclooxygenase-2 (COX-2), methyltransferase (DNMT-1, DNMT-3A and DNMT-3B), and histone deacetylase-1 (HDAC-1) in endometrial stem cells (ESCs) were derived from endometrium of endometrioma patients (OMA-ESCs) and deep infiltrative endometriosis samples of women with endometriosis associated infertility (E-ESCs) and ESCs derived from endometrium of endometriosis free, normal women (C-ESCs) in different Ceratonia siliqua L. pod extract (CPE) concentrations. The lines above the columns show significant differences $(p<0.05)$.
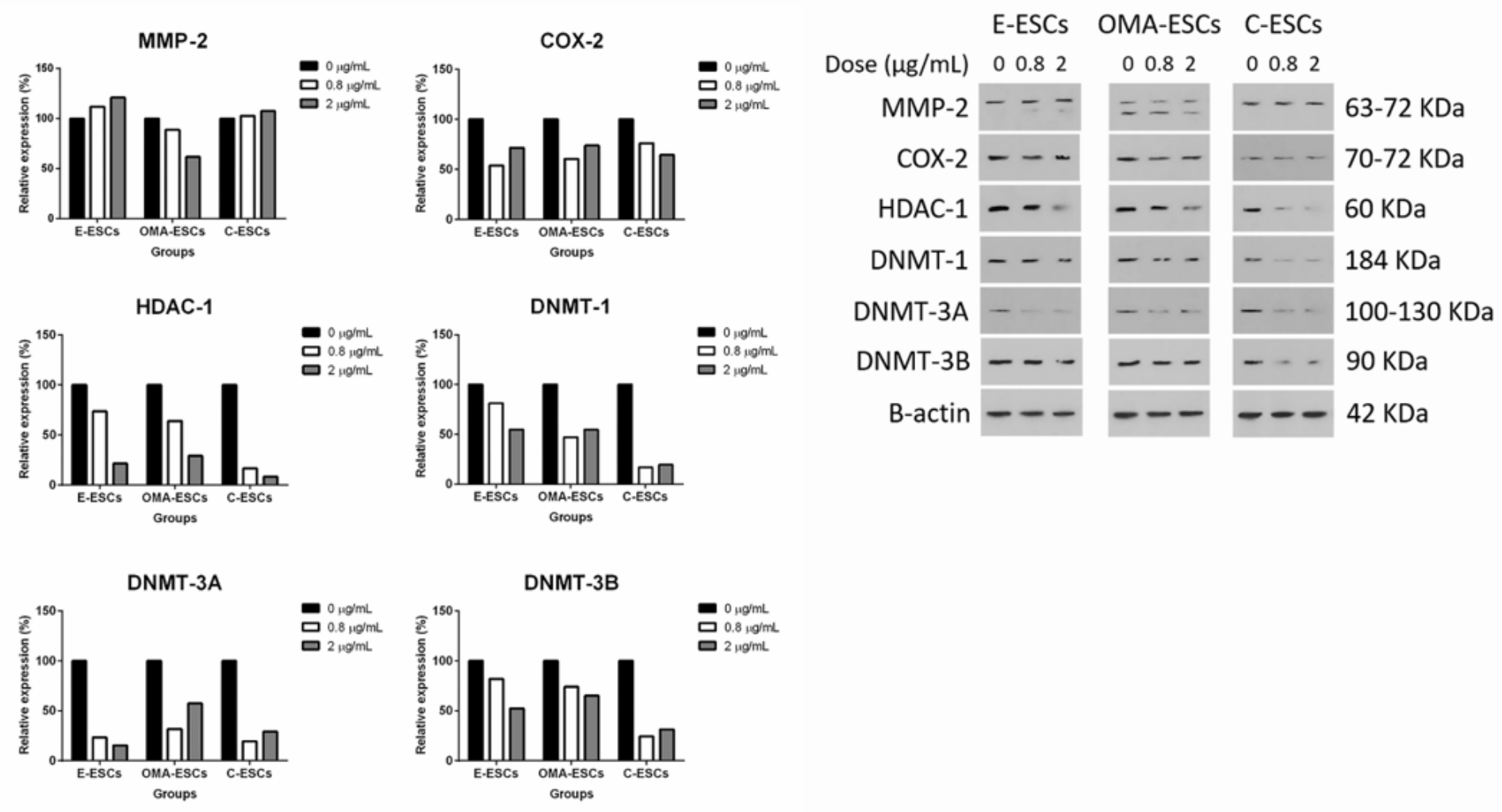

Figure 3

Relative peptide expression level (Mean \pm SD) of matrix metalloproteinase-2 (MMP-2), cyclooxygenase-2 (COX-2), methyltransferase (DNMT-1, DNMT-3A and DNMT-3B), and histone deacetylase-1 (HDAC-1) in endometrial stem cells (ESCs) were derived from endometrium of endometrioma patients (OMA-ESCs) and deep infiltrative endometriosis samples of women with endometriosis associated infertility (E-ESCs) and ESCs derived from endometrium of endometriosis free, normal women (C-ESCs) in different Ceratonia siliqua L. pod extract concentrations.

\section{Figure 4}

The 3D plot of the binding sites and the 2D plot of interactions of DNMT3A, COX-2, HDAC1, MMP2, DMNT1, and DNMT3B with different molecules in Ceratonia siliqua L. pod extract. Interaction of DNMT3A with A) A) 4-imidazolidinone, 1-benzoyl-2-(1-methylethyl)-3-methyl; B) benzene, 1,3,5-tris(1- 
methylpropyl)-; C) 3,4-dihydro-2(1H)-isoquinolinecarboximidamide; D) naphthalene,1,2,3,4-tetrahydro-1isopropyl-1,2,4,4,7-pentamethyl-; E) naphthalene, decahydro-2,3-dimethyl-; F) benzoic acid, 4-heptyl-, 4cyanophenyl ester; G) methanone,(1-hydroxycyclohexyl)phenyl-. Interaction of COX-2 with H) diphenyl sulfone; I) 3,4-dihydro-2(1H)-isoquinolinecarboximidamide; J) methanone,(1-hydroxycyclohexyl)phenyl; K) 4-imidazolidinone,1-benzoyl-2-(1-methylethyl)-3-methyl. Interaction of HDAC1 with L) benzoic acid, 4heptyl-,4-cyanophenyl ester. Interaction of MMP2 with M) diphenyl sulfone; N) methanone,(1hydroxycyclohexyl)phenyl-; 0) 3,4-dihydro-2(1H)-isoquinolinecarboximidamide; P) 4-imidazolidinone,1benzoyl-2-(1-methylethyl)-3-methyl. Interaction of DMNT1 with Q) naphthalene, 1,2,3,4-tetrahydro-1isopropyl-1,2,4,4,7-pentamethyl-. Interaction of DNMT3B with R) pentanoic acid, octyl ester; S) hexadecane; T) 2-methyl-5-(1-methylethenyl)-2-cyclohexen-1-ol; U) diethyleneglycol dimethacrylate; $\mathrm{V}$ ) naphthalene; W) 9-octadecenoic acid (Z)-,methyl ester; X) naphthalene,decahydro-2,3-dimethyl-.

\section{Supplementary Files}

This is a list of supplementary files associated with this preprint. Click to download.

- SupplementaryfileGCMStableCeratoniasiliqua.docx 